\title{
Publicacions del Dr. Joan Veny
}

\author{
M. ${ }^{a}$ ÀNGELS MASSIP
}

«Los supervivientes románicos de TALENTUM 'deseo', «dins: Revue de Linguistique Romane 21, 1957, 106-137 (amb un mapa.)

«Paralelismos léxicos en los dialectos catalanes», dins: Revista de Filología Española 42, 1958-1959, 91-149 (amb set mapes); 43, 1960, 117-202 (amb deu mapes.)

«Situació de la llengua catalana.-Els estudis lingüístics: el segle XVIII; des del 1814 al 1839. - Gramàtiques. Diccionaris. Activitat lexicogràfica.-Renovellament dels estudis linguiístics. Gramàtiques i diccionaris. Onomàstica i toponímia.-En les albors del segle XX. Alcover i el «Diccionari català-valencià-balear». Altres contribucions", dins: Un segle de vida catalana, Barcelona 1961, vol 1, 71-82, 320-322, 658-659; vol. 2, 979-981, 1472-1477.

Las dos lingüísticas. Lección inaugural del curso 1961-62 (Institut Nacional d'Ensenyament Mitjà de Lleida), Lleida, 1961.

«Atlas Lingüístic del Domini Català. Estado de los trabajos. Aspectos metodológicos» (en col-laboració amb A. M. Badia, G. Colon i M. Companys), dins: Actes du IX Congrès International de Linguistique Romane (Lisboa 1959), vol. 3, Lisboa 1962, 121-126.

«Notes phonétiques sur le parler de Campos (Majorque)», dins: Boletim de Filologia 20, 1962, 323-340.

«Notas léxicas sobre el habla de Campos (Mallorca)», dins: Orbis (Lovaina) 12/1, $1963,132-140$.

«L'estudi actual de la llengua catalana: homes i obres (1930-1960)», dins: La llengua catalana, II, Critèrion 26, 1965, 29-46.

«Atlas Lingüístic del Domini Català». Qüestionari (en col-laboració amb A. M. Badia Margarit), Barcelona: 1965.

«Cançons populars mallorquines», dins: Estudis Romànics 11 (Estudis de Literatura Catalana oferts a Jordi Rubió i Balaguer /2), 1962-1967, 305-325.

«Interés lingüístico del «Regiment de preservació de pestilència» de Jacme d'Agramont (s. XIV)», dins: Actas del IX Congreso Internacional de Lingüística y Filología Románicas (Madrid 1965), Madrid 1968, 1017-1029.

«Els noms de l' 'esternut' en català», dins Estudis Romànics 13 («Estudis de Lingüística i de Filologia catalanes dedicats a la memòria de Pompeu Fabra» / 2), 1963-1968, 95-125 (amb un mapa). 
«Regiment de preservació de pestilència» de Jacme d'Agramont (s. XIV). Introducció, transcripció i estudi lingüístic. Tarragona: Diputació 1971.

«Dialectologie catalane», dins: Antonio Badia Margarit, Georges Straka (eds.), La Linguistique catalane (Actes et colloques 11), Paris 1973, 289-337 (amb vuit mapes.)

«La nostra llengua», dins: Campos, ahir i avui, Campos (Mallorca) 1974, 78-93.

«El valencià meridional», dins: Problemes de llengua i literatura catalanes. Actes del II Col-loqui Internacional sobre el català (Amsterdam 1970), Montserrat 1976, 145180 (amb 50 mapes.)

Llucmajor a través de la seva toponímia. Llucmajor (Mallorca) 1976.

«Interferencias léxicas en catalán», dins: Alberto Vàrvaro (ed.), XIV Congresso Internazionale di Linguistica e Filologia Romanza (Napoli 1974). Atti, vol. 4, NapoliAmsterdam 1977, 211.231 (amb tres mapes.)

«Problemas de ictionimia catalana», dins Manuel Alvar (ed.), Actas del V Congreso Internacional de Estudios del Mediterráneo (Málaga 1973), Madrid 1977, 315-329 (reproduït a Manuel Alvar (ed.), Terminología marinera del Mediterráneo, Madrid 1977, 309-323.)

«Aproximació a l'estudi del dialecte eivissenc», dins: Randa 5, 1977, 5-41 (amb un mapa).

Estudis de geolingüística catalana. Barcelona: Edicions 62, 1978 (amb vint-i-sis mapes; 2. a ed., 1984.)

Els parlars. Barcelona: Dopesa 1978. (Conèixer Catalunya.), 2. ${ }^{a}$ ed., Els parlars. Síntesi de dialectologia catalana, Barcelona: Dopesa 1980.

«De la bèl-lua al tauró: supervivents catalans del llatí PISTRIX», dins: Randa 9 (Homenatge a Francesc de B. Moll /1), 1979, 51.62.

«Sobre els castellanismes del rossellonès», dins: Hommage à Jean Séguy, vol. 2, Toulouse 1979, 401-438 (amb cinc mapes.).

«Dialectalismes en els poetes lleidatans», dins: Homenatge a Samuel Gili Gaya (in memoriam), Barcelona 1979, 193-200.

«Obres de lingüística catalana», dins Serra d'Or 233, 1979, 50-54.

«Problemas de adstrato en catalán», dins Archivum [Estudios ofrecidos a Emilio Alarcos Llorach con motivo de sus XXV años de docencia en la Universidad de Oviedo ] 29 $30,1979-1980,399-422$.

«Antroponímia i lingüística diacrònica», dins Societat d'Onomàstica, Butlletí interior 1, 1980, 38-39.

«Dialectologia i cultura popular», dins: Lluc 691, maig-juny 1980, 12-13.

«Cartografia lingüística», dins: La cartografia al servei de les autonomies. Ponències, comunicacions i col-loquis de les Jornades de Cartografia temàtica. Associació Catalana de Ciència Regional (1979), Barcelona 1980, 87-97.

«Sobre els occitanismes del rossellonès», dins: Jordi Bruguera, Josep Massot i Muntaner (eds.), Actes del V Col-loqui Internacional de Llengua i Literatura Catalanes (Andorra 1979), Montserrat 1980, 441-494 (amb cinc mapes.)

«Transfusió i adaptació d'ictiònims en el «Dictionarium» de Pere Torra», dins: Estudis de Llengua i Literatura Catalanes 1 [Homenatge a Josep M. de Casacuberta / 1], 1980, 69-102. 
«El cognom Gamundí/Gamundi, germanisme o arabisme?», dins: Miscel-lània Aramon $i$ Serra. Estudis de Llengua i Literatura Catalanes oferts a R. Aramon $i$ Serra en el seu setantè aniversari 2 , Barcelona 1980, 584-595 (amb un mapa.)

«De re ficaria: cat. 'bordissots' i 'paratjals'», dins: Affar 1, 1981, $37-46$ (amb dos mapes.) «Notícia d'obres de lingüística catalana (1978-1979)», dins Serra d'Or 256, 1981,43-46. «Homenatge al Sr. Francesc de B. Moll», dins: Homenatge a Francesc de B. Moll, Mallorca 1982, 4-7.

Els parlars catalans (Síntesi de dialectologia), 3. ${ }^{\mathrm{a}}$ ed. corregida i augmentada. Palma de Mallorca: Moll 1982. (Raixa 128.) (9. ${ }^{a}$ ed. 1991.)

"Influència del Diccionari català-llatí de Font sobre el de Torra», dins: Estudis de Llengua i Literatura Catalanes 6 [Homenatge a Pere Bohigas/3], 1983, 11-24.

«Introducción a la gramática catalana», dins: Avances del saber, vol. 12, Barcelona 1984, 688-721.

«Dialecte i llengua», dins: Els Marges 30, 1984, 11-28.

«Lexicografia i dialectalismes: a propòsit del Diccionari català-llatí d'Antoni Font (s. XVII)», dins: Estudis en memòria del professor Manuel Sanchis Guarner: Estudis de llengua i literatura catalanes, vol. 1, València 1984, 381-190 (reeditat a Antoni Ferrando (ed.), Miscel-lània Sanchis Guarner, vol. 3, Montserrat 1992, 351-359.)

«Etimologia ictionímica: el català PETARC 'crenilabrus scina'», dins J. L. Melena (ed.), Symbolae Ludovico Mitxelena septuagenario oblata, vol. 1, Vitoria 1985, 753761.

«[Patit tractat sobre lo regiment en temps de hepidèmie] (s. Xv). Edició i estudi lingüístic», dins: Homenatge a Antoni Comas, Barcelona 1985, 545-567.

Introducció a la dialectologia catalana. Barcelona: Fundació Enciclopèdia Catalana 1986. (Biblioteca Universitària 4.)

«L'ètim de MERITA 'fredeluga': entre l'arabisme i l'onomatopeia», dins Estudis de Llengua i Literatura Catalanes 12 [Miscel-lània Antoni M. Badia Margarit / 4 ], 1986, 37-61 (amb un mapa.)

«Aproximación a la lengua catalana», dins Manuel Alvar (ed.), Lenguas peninsulares y proyección hispánica, Madrid 1986, 93-106.

«La dialectologia catalana: realitats i perspectives», dins Joan Veny, Joan M. Pujals (eds.), Actes del Setè Col-loqui Internacional de Llengua i Literatura Catalanes (Tarragona-Salou 1985), Montserrat 1986, 383-423.

«Dialectalismes a les «Visions de Mallorca» de Joan Santamaria», dins Miscel-lània. Homenatge a Josep Vallverdú, Lleida 1987, 319-337.

«Atlas Lingüístic del Domini Català», dins Anthropos 81 (Antoni M. Badia Margarit. Amor y pasión por una lengua y una cultura), 1988, 7-8.

«De malicA a les 'figues melenquines'», dins Studia in honorem Prof. M. de Riquer, vol. 3, Barcelona 1988, 177-194.

«Origen dels cognoms catalans MIRABENT i PORCET», dins Albert Manent, Joan Veny (eds.), Miscel-lània d'homenatge a Enric Moreu-Rey, vol. 3, Montserrat 1988, 281-295.

«Noves dades sobre la partió català occidental-català oriental», dins Philip D. Rasico, Curt J. Wittlin (eds.), Actes del V Col-loqui d'Estudis Catalans a Nord-Amèrica (Tampa-St. Augustine 1987), Montserrat 1988, 11-36 (i cinc mapes.) 
«CATXEL 'cardium edule', un nou mossarabisme del català», dins G. Holtus, G. Lüdi, M. Metzeltin (eds.), La Corona d'Aragó i les llengües romàniques. Miscel-lània d' homenatge a Germà Colon, Tübingen 1989, 463-475.

«Llei fonètica, onomatopeia i polisèmia en els noms catalans del 'grill'», dins Anna Cornagliotti et al. (eds.), Miscellanea di Studi Romanzi offerta a Giuliano Gasca Queirazza, vol. 2, Torino 1988, 1073-1095.

«L'equivalència acústica $B=G$ en català: els casos de BOLERANY 'remolí' i BOIXAC 'galdiró'», dins Estudis de Llengua i Literatura Catalanes 18 [Miscel-lània Joan Bastardas / 1], Montserrat 1989, 101-127.

«Cap a una tipologia de l'etimologia popular», dins Profesor Francisco Marsá. Jornadas de Filologia, Universitat de Barcelona 1990, 137-152.

«Mots d'ahir i mots d'avui», dins VII Jornades sobre expressió escrita, Escola Universitària del Professorat, Universitat de Barcelona 1990, 15-32.

«Sobre les equivalències castellà /x/ = català / $¥ / »$, dins Homenaje a Alonso Zamora Vicente, vol. 2, Madrid 1990, 307-321 (amb un mapa.)

«Areallinguistik. Áreas lingüísticas», dins G. Holtus, M. Metzeltin, C. Schmitt (eds.), Lexikon der Romanistischen Linguistik, vol. 5/ 2. Tübingen 1991, 243-261.

«Francesc de B. Moll, dialectòleg», dins Anuari de l'Institut d'Estudis Catalans. Curs 1990-1991, Barcelona 1991, 88-94.

«Huellas aragonesas en los dialectos catalanes meridionales», dins Actas del I Congreso de lingüistas aragoneses (Zaragoza 1988), Zaragoza 1991, 89-102.

Mots d'ahir i mots d'avui. Barcelona: Empúries 1991. (Biblioteca Universal Empúries 51.)

«Les varietats geogràfiques i la normativa de la llengua catalana», dins J. Martí Castell (ed.), Processos de normalització lingüística: l'extensió d'ús social i la normativització, Barcelona 1991, 197-205.

«Francesc de B. Moll, dialectòleg», dins Acte d'homenatge a Francesc de B. Moll, Universitat de Barcelona 1992, 21-29.

«Où va la dialectologie?», dins Quaderni di semantica 12/ 2, 1991, 317-325.

«Baleares, confluencia de culturas», dins Baleares, hoy, Palma de Mallorca 1992, 183-186.

Espècies pesqueres d'interès comercial (en col-laboració amb Montserrat Alegre i Jordi Lleonart). Barcelona: Departament de Cultura 1992.

«El meu Jaume Vidal», dins Homenatge a Jaume Vidal Alcover, Barcelona 1992, 179190.

«De l'occità GRONAU al català GARnEU 'Trigla lyra'», dins K. I. Kobbervig, A. Pacheco, J. Massot i Muntaner (eds.), Actes del Sisè Col-loqui d'Estudis Catalans a NordAmèrica (Vancouver 1990), Montserrat 1992, 60-88.

«Les varietats dialectals i els estudis dialectològics», dins Isidor Marí (ed.), Segon Congrés Internacional de la Llengua Catalana. IV. Àrea 3. Lingüística social, Palma de Mallorca 1992, 21-48.

«El futuro de la dialectología catalana», dins Revista de Lengua y Literatura catalana, gallega y vasca 2, 1992, 29-42.

«Llengua històrica i llengua estàndard a la Plana de Vic», dins Ausa 14, 1991, 315-324.

«Fronteras y áreas dialectales», dins Actas del Congreso Internacional de Dialectología (Bilbao 21-25.X.1991), Bilbao 1992, 197-245. 
«Nécrologes...Enric Moreu-Rey (1917-1992)», dins Nouvelle Revue d'Onomastique 1920, 1992, 282-283.

Atles Lingüístic del Domini Català. Qüestionari (en col-laboració amb Antoni M. Badia Margarit i Lídia Pons). Barcelona 1993. (Biblioteca de Dialectologia i Sociolingüística 2.)

«Els 'joglars' de la mar», dins Estudis de Llengua i Literatura Catalanes 26 [Miscel-lània Jordi Carbonell 5 ], 1993, 158-175.

«Actituds metalingüístiques en textos dialectals», dins Col-loqui sobre les Fonts Orals (Monestir de la Real, Palma 12-15 abril 1984), Universitat de les Illes Balears, 1992, 57-61.

«El valencià antic SAURA 'gralla' no és un mot fantasma», dins A. Ferrando, A. Hauf, Miscel-lània Joan Fuster. Estudis de Llengua i Literatura, Montserrat 1993, 307-317.

«Dos caballas advenedizas en dominio catalán», dins Antiqua et nova Romania. Estudios lingüísticos y filológicos en honor de José Mondéjar en su sexagésimoquinto aniversario, vol. 1, Universidad de Granada 1993, 505-524.

«Aproximació a la història lingüística dels vins catalans», dins Vinyes $i$ vins: mil anys d'història. Actes $i$ comunicacions del III Col-loqui d'Història Agrària sobre mil anys de producció, comerç $i$ consum de vins $i$ begudes alcohòliques als Països $\mathrm{Ca}$ talans. Febrer de 1990, Universitat de Barcelona 1993, 103-115.

Dialectologia filològica. Transfusió lèxica. Llengua escrita i dialectalismes. Barcelona: Curial / Publicacions de l'Abadia de Montserrat 1993. (Textos i Estudis de Cultura Catalana 33.)

«Origine de l'ichtyonyme hispanique BaILA 'dicentrarchus punctatus'», dins G. Hilty, Actes du XX Congrès International de Linguistique et Philologie Romanes (Zurich 1992), vol. 4, Tübingen 1993, 761-774.

«Fortuna del fonema / $\mathrm{x}$ / en català: visió històrica de la 'queada'», dins R. Alemany, A. Ferrando, LI. B. Meseguer (eds.), Actes del IXè Col-loqui Internacional de Llengua i Literatura Catalanes (Alacant / Elx 1971), vol. 2, Montserrat 1993, 405-436.

«La repercussió de l'obra de Lorenzo Palmireno en la filologia catalana», dins Caplletra 11 [ J. Colomina i Castanyer (ed.), Actes del Simposi «Cent Cinquanta Anys de Filologia Valenciana (1800-1950) « ], 1990, 69-90.

«Yeísmo histórico y tratamiento de / $\mathrm{x} /$ en asturiano y catalán», dins Lletres asturianes 50 , 1993, 27-37.

«El valencià en la proposta del català estàndard», dins Jornades de la Secció Filològica de l'Institut d'Estudis Catalans a Castelló (16-17 octubre 1992), Barcelona-Caste1ló, 1993, 47-56.

«Atlas Lingüístic del Domini Català $(A L D C)$. Estat actual dels treballs» dins Bollettino dell' Atlante Linguistico Italiano", III Serie, 11-16 (1987-1992), 1993, 105-112.

(en col-laboració amb Lídia Pons Griera) «Atlas Lingüístic del Domini Català»: estado de los trabajos», dins Pilar García Mouton (ed.), Geolingüística. Trabajos europeos, Madrid 1994, 253-273.

«Contacte de llengües en la llista de peixos de Jordi de Puig (1786)», dins Estudis de Llengua i Literatura Catalanes 29 [Miscel.lània Germà Colon/2 ], 1994, 77-94.

«Esperit i esdevenidor de la llengua catalana. Vitalitat de la parla. Els dialectes», dins Raimon Panikkar (ed.), Llenguatge i identitat. Lexicosofia catalana, Montserrat 1994, 247-266. 
La lliçó lingüística de Maria Antònia Salvà. Llucmajor: 1995. (Papers de l'Allapassa 7.) «La importación del fonema /x/ en catalán», dins Revista Española de Lingüística 24/1, 1994, 1-19.

«Quedar amb ses llànties de Campos», dins Festes de la Mare de Déu d'Agost 1995, Campos 1995, 4-6.

Francesc de B. Moll: ciència i humanitat. Mallorca: Estudi General Lul-lià 1995.

«El Diccionari de la Llengua Catalana, una obra actual i integradora», dins El Mirall 77, 1996, 6-8-

«Erotisme i litúrgia en els noms del QUETSÉMPER (Synodus saurus L.)», dins Estudis de Lingüística i Filologia oferts a Antoni M. Badia i Margarit, vol. 3, Universitat de Barcelona / Abadia de Montserrat, 1996, 289-309.

«Langue historique et langue standard dans le domaine catalan», dins La Bretagne Linguistique 10, 1996, 386-394.

«El Diccionari Alcover-Moll», dins Joan Francesc March (ed.), Segon llibre de lectures mallorquines, Mallorca 1996, 95-100.

«Els mallorquinismes en les Visions de Mallorca de Joan Santamaria», dinsUrc 10, $1996,52-68$.

«Presentación do Atlas Lingüístico Galego (A Coruña, 21 marzo 1996)», dins Cadernos de lingua 13, 1996, 147-152.

Onomàstica i dialectologia. Montserrat: Publicacions Abadia de Montserrat 1996. (Biblioteca Serra d'Or 166.)

«Gènesi, mètode, estructura i valoració del 'Diccionari català-valencià-balear' », dins Lèxic, corpus i diccionaris. Cicle de conferències 94-95 (Institut Universitari de Lingüística Aplicada. Universitat Pompeu Fabra), Barcelona 1996, 23-33.

«Asedio dialectológico a la lengua / Setge dialectològic a la llengua», dins Mapamundi catalán estense. Escuela cartográfica mallorquina, Barcelona 1996, 73-74, 136-137.

«Le domaine catalan», dins Michel Contini-Gaston Tuaillon, Atlas Linguistique Roman (ALiR), Roma, 1996, 45-53.

«Onomàstica i dialectologia», dins Jordi Costa (ed.), Onomàstica a la Catalunya del Nord. Actes del XXè Col-loqui General de la Societat d'Onomàstica (Perpinyà 17-18 febrer 1995), Perpinyà 1997, 13-34.

«El catalán, ayer y hoy», dins M. Luisa Arnal i Javier Giralt (eds.), Actas del Encuentro 'Villa de Benasque' sobre lenguas y culturas pirenaicas (Benasque 1996), Zaragoza, Diputación General de Aragón, 1997, 167-183.

«Ittionimia catalana: nuove proposte etimologiche», dins Gianna Marcato (ed.) I dialetti e il mare. Atti del Congresso Internazionale di studi in onore di Manlio Cortelazzo (Chioggia, 21-25 settembre 1996), Padova 1997, 13-30.

«Dialectologia contrastiva», dins Jornades de la Secció Filològica de l'Institut df' Estudis Catalans a Mallorca (18 i 19 d'octubre de 1996), Barcelona-Palma, IEC-Universitat de les Illes Balears, 1997, 17-31.

«Els noms catalans del 'mosquit', «Revista de Filología Románica [Memoria-Homenaje a Pedro Peira Sobeirón] (Madrid), 14/2, 1997, 487-501.

«Joan Coromines, dialectòleg», dins Escola Catalana, 341, 1997, 8-10. 
«Les noms catalans du 'Bothus podas (Delaroche 1809)' et d'autres pleuronectiformes», dins «Les Zoonymes». Publications de la Faculté des Lettres, Arts et Sciences Humaines de Nice, Nouvelle série n. ${ }^{\circ} 38$, Nice, 1997, 387-405.

«Tradición e innovación en los nombres catalanes del 'Eryobotria japonica' y su fruto», dins G. Ruffino (ed.) Atti del XXI Congresso Internazionale di Linguistica e Filologia Romanza (Palermo 1995), Tübingen, Max Niemeyer, III, 1998, 927-940.

«L'alguerès i la llengua estàndard», dins Paolo Maninchedda (ed.), La Sardegna e la presenza catalana nel Mediterraneo. Atti del VI Congresso (III Internazionale) di Studi Catalani (Cagliari 1995), Cagliari, Cooperativa Universitaria Editrice Cagliaritana, I, 1998, 555-566.

Els parlars catalans (Síntesi de dialectologia catalana), edició revisada i augmentada, Mallorca, Moll, 1998, 173 pàgs.

«Scripta i projecció dialectal en català», dins Dietrich Briesemeister / Axel Schönberger (eds.), Ex nobili philologorum officio: Festschrift für Heinrich Bihler zu seinem 80. Geburtstag, Berlin, Domus Editoria Europaea, 1998, 888-891.

«Diatopismes en la poesia de Damià Huguet», dins Biel Huguet/Montserrat Alcaraz (eds.), Damià Huguet, home de call vermell, Binissalem, 1998, 134-144.

«Semblança d'Antoni M. Alcover i Sureda», dins Institut d'Estudis Catalans, Memòria. Curs 1997-1998, Barcelona, 1999, 108-116.

Aproximació al dialecte eivissenc, Mallorca, Moll, 1999, 181 pàgs.

«La geolingüística catalana, ahir i avui», Caplletra (València), 25, 1999, 109-134.

«Leuconíquia i cultura popular», Caplletra, 26, 1999, 27-37.

«El mestratge d'Antoni M. Badia Margarit», Revista de lenguas y literaturas catalana, gallega y vasca, 6, 1999, 273-278.

«Centralització d'o àtona en català», Catalan Review, 13/1-2, 1999 [Homage Volume for Professor Joseph Gulsoy ], 225-253.

«Topònims i gentilicis en la ictionímia catalana», dins Joan F. Mateu i Emili Casanova (eds.), Estudis de Toponímia Valenciana en honor de Vicenç M.Rosselló $i$ Verger, València, 2000, Denes, 529-540.

«Gallec i català: relacions i paral-lelismes lingüístics», in Professor Basilio Losada / Ensinar a pensar con liberdade e risco, Universitat de Barcelona, 2000, 708-720.

«De la 'nineta' a l' 'ànima de l'ull'», Jornades de la Secció Filològica de l'Institut d'Estudis Catalansa a Elx i a la Univesitat d' Alacant, Barcelona-Elx, I.E.C., Ajuntament d'Elx, 2000, 83-92.

Giovanni Palomba, Nuova grammatica del dialetto algherese odierno, edició i anotació de J. Veny, introducció d'August Bover, Alghero, 2000: La Celere.

Llengua i entorn natural, Barcelona, Edicions 62, 2001.

«Diatopia i llengua estàndard», in Miquel À. Pradilla (ed.), Societat, llengua i norma. A l'entorn de la normativització de la llengua catalana, Benicarló, Ed Alambor, 2001, 207-272.

«L'onomàstica a través de la història de Llucmajor», in Bartomeu Font Obrador, Historia de Llucmajor, IX, Mallorca, 2001, 9-26.

Llengua històrica i llengua estàndard, València, 2001, Publicacions de la Universitat de València, 2001 («Biblioteca Lingüística Catalana», 26), 268 pàgs.

«Varietats geogràfiques», dins F. Vallverdú (director), Enciclopèdia Lingüística Catalana, Barcelona, 2001, Eds. 62, 172-180. 
«Jaume Vidal Alcover i la llengua» dins Magí Sunyer i Rosa Comes (eds.), Jaume Vidal Alcover: humanisme, heterodòxia i geni, Valls, 2001, Cossetània Edicions-Universitat Rovira i Virgili, 175-188.

Llengua i religió a Mallorca, Pregó de la Setmana Santa, Campos, 2002, 17 pàgs.

«El valencià en l'Atles Lingüistic del Domini Català», dins Emili Casanova, Joaquim Martí i Abelard Saragossà (eds.), Estudis del valencià d'ara. Actes del IV Congrés de Filologia Valenciana del 20 al 22 de maig de 2000 en homenatge al doctor Joaan Veny, València, 2002: Denes, 641-657.

«Busnada 'tronada, pluja forta', arabisme o romanisme?», Estudis de Llengua i Literatura Catalanes, LXIV [Miscel-lània Giuseppe Tavani/3], Barcelona, 2002, 261-269.

«Presentació del primer volum de l'Atles Lingüistic del Domini Català», in Institut d'Estudis Catalans, Atles Lingüístic del Domini Català. Presentació del primer volum, Barcelona: Institut d'Estudis Catalans [Publicacions de la Presidència, 15], 2002, 31-38.

«La interferència occitana en l'obra epidemiològica d'Antoni Girauld», in Michel Aurnague i Michel Roché (eds.), Hommage à Jacques Allières 2. Romania sans frontières, Anglet, 2002: Atlantica, 637-651.

«Sobre el mallorquí aluleia 'cridòria' i el sufix -eia», Randa, 50 [Homenatge a Miquel Batllori/3], 2003, 219-228.

"Treinta años de lingüística catalana», in Alberto Bernabé et al. (eds.), Actas del Segundo Congreso de la Sociedad Epañola de Lingüística (Madrid, 11-15 diciembre 2000). Presente y futuro de la Lingüística en España. La Sociedad de Lingüística, 30 años después, I, Madrid, 2001, 291-324.

«Sobre el valencià gemecar», Caplletra, 32, 2002, 143-155.

«El Diccionari Alcover-Moll», dins Any Mossèn Alcover. Presentació de la Lletra de convit 2001, Barcelona, 2003, Institut d'Estudis Catalans, Publicacions de la Presidència, 16-21.

«Francesc de B. Moll, codificador de la varietat balear: una mostra», Estudis Baleàrics [Centenari de Francesc de B. Moll (1903-2003)], núm. 72-73, 2002: 65-79.

«Escriptura i oralitat a Mallorca», Mallorca, 2003: Moll.

«Germà Colón o la passió per les paraules», Saó [València], 2003, 41-51.

«Antoni M. Alcover i la dialectologia catalana», Actes del Congrés Internacional Antoni M. Alcover, Barcelona: Càtedra A. M. Alcover-F. de B. Moll-M. Villangómez, 2003, 9-38.

«Relacions toponímiques i lingüístiques entre les Balears i la Marina», Actes del XXIX Col-loqui de la Socitat d'Onomàstica (Teulada [Marina Alta], 6-8 desembre 2002), València, 2003, 705-730.

«Catalán: historia externa de la lengua», dins G. Ernst, M.-D. Gessgen, C. Schmitt i W. Schweickard (eds.), Romanische Sprachwissesnschaft. Histoire linguistique de la Romania. Ein internationales Habdbuch zur Geschichte der romanischen Sprachen. Manuel international d'histoire linguistique de la Romania, I, Berlin-New York: W. de Gruyter, 2003, 840-852.

"Qüestions geolingüístiques a l'entorn de la varietat tortosina», dins Miquel Àngel Pradilla (ed.), Llengua i Literatura a les comarques de la diòcesi de Tortosa, Benicarló, 2003: Onada Edicions, 351-380.

«Francesc de B. Moll, dialectòleg», in Maria Pilar Perea (ed.), Francesc de B. Moll a l' $i$ nici del segle XXI, Barcelona: Publicacionsde la Universitat de Barcelona, 57-67. 
«Codification dialectale et polymorphisme dans la Nuova Grammatica (1945) de Palomba", in Rita Caprini (ed.), Parole romanze. Scritti per Michel Contini, Alessandria, 2003, 483-496.

«Diatopisme i estàndard en català», in Premis de la Fundació Catalana per a la Recerca. Convocatòria 2004, Barcelona: Sèrie de Publicacions de la Fundació Catalana per a la Recerca, 21-26.

«Ictionímia balear», Actes del VIè Congrés. El Nostre Patrimoni Cultural. El Patrimoni Marítim i Costaner, Palma de Mallorca, 2004, 15-30.

"Contribució de la dialectologia a la gramàtica», dins Maria-Rosa Lloret - Clàudia Pons (eds.), Lingüística i gramàtiques, Barcelona, 2004: Departament de Filologia Catalana de la Universitat de Barcelona - Promociones y Publicaciones Universitarias, 109-151.

«Rector i rectoria en català: estudi onomasiològic», in Germà Colón - Tomàs Martínez Maria Pilar Perea (eds.), La cultura catalana en projecció de futur. Homenatge a Josep Massot i Muntaner, Castelló, 2004: Fundació Germà Colón i Domènech, 473-493.

«Sobre la interferencia catalán-castellano», dins A. Gil, D. Osthus i C. Pozin-Haumann (eds.), Romanische Sprachwissenschaft. Zeugnisse für Vielfalt und Profil eines Faches. Festschrift für Chistian Schmitt zum 60. Geburtstag, Frankfurt am Main: Peter Lang, 2004, I, 339-354.

"Afinitats ultrapirinenques del català septentrional de transició», in Xavier Luna-Batlle (ed.), Actes del Col-loqui L'Albera i el patrimoni en l'espai transfronterer, Figueres, 2005: Consell Comarcal de l'Alt Empordá, 179-199.

"Alguns ensenyaments de la geolingüística», in Els mètodes en dialectologia: continuïtat o alternativa? I Jornada Filològica de l'Associació Amics d'Antoni M. Badia i Margarit, Barcelona, IEC, 2005, 155-172 i 5 mapas.

El primer diccionari mallorquí de l'autor llucmajorer Pere Antoni Figuera, pregó de Fires 2004, Llucmajor, Ajuntament, 2005, 27-46.

"Norma i espai», dins Bàrbara Roviró, Aina Torrent-Lenzen i Andreas Wesch (ed), Normes $i$ identitats. Normen und Identitäten. Sprachwissenschaftliche Beiträge des 19. Deutschen Katalanistentags Köln 2003, Titz: Axel Lenzen Verlag, 2005, 291-320.

Tradició, traducció i interferència en el diccionari mallorqui (1840) de Pere Antoni Figuera, Palma: Consell de Mallorca, 2006.

Contacte $i$ contrast de llengües $i$ dialectes, València, Universitat de València, 2006 (Biblioteca Linguística Catalana/30).

(En col-laboració amb J. Arrizabalaga i L-García Ballester), «Estudi introductori i edició del Regiment de preservaciô de pestilència de Jacme d'Agramont», dins Jacme d'Agramont, Regiment de preservació de pestilència $(s . x \mathrm{~N})$, Barcelona, Enciclopèdia Catalana, 1998, 35-45 i 49-90.

(En col-laboració amb Lídia Pons) Attes Lingüístic del Domini Català.. Etnotextos del català oriental, Barcelona, Institut d'Estudis Catalans, Biblioteca de Dialectologia i Sociolingüística, V, 1998 (obra acompanyada d'una casset amb 31 etnotextos enregistrats).

(En col-laboració amb Lídia Pons): Atles Lingüístic del Domini Català, I. Introducció. 1 . El cos humà. Malalties, Barcelona, 2001, Institut d'Estudis Catalans.

(En col-laboració amb Lídia Pons): Atles Lingüístic del Domini Català, II. 2 El vestit. 3. La casa i ocupacions domèstiques, Barcelona, 2003: Institut d'Estudis Catalans. 
(En col-laboració amb J. E. Gargallo) «Synthèse romane de 'grillon'», dins Atlas Linguistique Roman (ALiR), II a, Commentaires, Roma, Istituto Poigrafico e Zecca dello Stato, 2001, 201-217.

(En col-laboració amb J. Saramago) «Synthèse romane de 'moustique'», dins Atlas Linguistique Roman (ALiR), II a. Commentaires, Roma, Istituto Poigrafico e Zecca dello Stato, 2001, 359-376.

(En col-laboració amb Mar Massanell) Dialectologia catalana, Barcelona, 2002, Universitat Oberta de Catalunya, 305 pàgs.

(En col-laboració amb Lídia Pons) «La perspectiva lingüística: l'Atles Lingüístic del Domini Català. Etnotextos i material cartogràfic», dins Lourdes Plans i Campderrós (ed.), Fonts orals. La investigació a les terres de parla catalana. Actes de les Jornades de la Coordinadora de Centres d'Estudis de Parla Catalana, Barcelona, 2003, 205-218.

(En col-laboració amb Ángels Massip) «Scripta et projection diatopique», dins C. D. Pusch, J. Kabatek i W. Raible (eds.), Romanistische Korpuslinguistik Il. Korpora und diachrone Sprachwissenschaft, Tübingen, Gunter Narr, 2005: 253-261.

«Le relazioni catalano-genovesi e il loro riflesso linguistico», Una lingua del mare. Il genovese tra Liguria e Mediterraneo - I Convegno Internazionale di studi (GenovaArenzano, 1998) (en premsa).

«Consideracions al voltant de l'onomàstica de Menorca», XXIII Col-loqui de la Societat de' Onomàstica, Maó i Ciutadella (22-24 març 2002) (en premsa).

«Afinitats ultrapirinenques del català septentrional de transició», in L'Albera i el patrimoni en l'espai transfronterer, Figueres, 2004 (en premsa).

(En col-laboració amb Àngels Massip) «Corpus de diatopie diachronique de la langue catalane», dins 2 Freiburger Arbeitsagung zur romanistischen Korpuslinguistik (11-13 setembre 2003, Freiburg im Breisgau) (en premsa).

«Diacronia i diatopia en el català baleàric segons dades del projecte de recerca Scripta $i$ projecció dialectal,», Actes del Simposi Internacional Vers una sintaxi històrica del català: metodologia $i$ objectius», La Nucia (Alacent), 12-14 novembre 2003, (en premsa).

«Sobre els significants de 'blasfemar' i 'renyar': geolingüística, semàntica i etimologia», Caplletra, 2004 (en premsa)

«Francesc de B. Moll i l'etimologia catalana», Actes del Congrés Internacional Francesc de B. Moll (Palma, 17-21 novembre 2003) (en premsa).

«Alguns ensenyaments de la geolingüística», Jornada Filològica organitzada per l'associació Amics d'Antoni M. Badia margarit, IEC, 11 març 2004 (en premsa).

«El primer diccionari mallorquí de l'autor llucmajorer Pere Antoni Figuera», pregó de Fira, Llucmajor, 28 setembre 2004.

Tradició, traducció $i$ interferència en el diccionari mallorquí (1840) de Pere Antoni Figuera, Llucmajor (en premsa).

Escrits lingüístics mallorquins, Palma de Mallorca, 2005 (en premsa).

Epistolari de Maria-Antònia Salvà a Miquel Roig: mestratge i amistat, Llucmajor, 2005 (en premsa).

«Llengua i territori en l'obra de Verdaguer», Actes del Col-loqui Verdaguer: llengua, retòrica i poètica, novembre 2005 (en premsa). 
«Joan Coromines, etimòleg», Actes del Col-loqui sobre Joan Coromines, Universitat Autònoma de Barcelona, Bellaterra, 2005 (en premsa).

«Germà Colón, etimòleg, Homenatge Universitat de València, 2006 (en premsa). Nomenament de fill il-lustre de Campos, 2006 (en premsa).

(en col-laboració amb José Enrique Gargallo) «Moineau. Synthèse romane», Atlas Linguistique Roman (ALiR), vol. Ilb, Roma, Istituto Poligrafico e Zecca dello Stato, (en premsa).

Col-laboració a Gran Enciclopedia Larousse, Barcelona 1967-1972; Gran Enciclopèdia Catalana., Barcelona 1969-1980; Atlas de Catalunya. Geogràfic, econòmic, històric, Barcelona 1974; Acadèmia de Ciències Mèdiques de Catalunya i Balears, Vocabulari mèdic, Barcelona 1974.

Manual de dialectologia catalana (en col-laboració amb Mar Massanell), Barcelona, Universitat Oberta de Catalunya.

\section{ALTRES PUBLICACIONS (articles breus o no lingüístics)}

«La peculiaridat dialectal campanera», dins Fiestas Populares. Campos del Puerto, 1961, 5-6 i Fiestas de la "Mare de Déu d"Agost", Campos, 1962, 5-6 (i reproduït a Diario de Mallorca, 14.08.1980.)

«Topònims àrabs i mossàrabs dins el terme de Campos», dins Fiestas Campos, 1963, 9-10. «Dues notes sobre Fra Joan Ballester, O.C.», dins Fiestas Campos, Campos 1964, 5-6. «Ullada sobre la toponímia del terme de Campos», Fiestas patronales, Campos, 1965, 5-7. El historiador mallorquín Francesc Talladas (1746-1818), discurso biográfico pronunciado el 15 de agosto de 1962, Campos (Mallorca), 1966.

«L'historiador mallorquí Francesc Talladas (1746-1818)», dins Homenatge a Jaume Vicenç Vives, vol. 2, Barcelona, 1967, 755-760.

«Evocació d'un mestre», dins Fiestas patronales de Campos, Campos, 1968, 12-13.

«Fabra i els dialectes», dins Lluc, abril 1968, 9-10.

«El llegat lingüístic mallorquí a Tàrbena (Alacant)», dins Lluc, maig 1972, 18-20 (amb un mapa.)

«Els nostres peixos», dins Fiestas de San Jaime, Santanyí (Mallorca), 1976.

«L'obra de Madò Coloma», dins Homenatge a Madò Coloma al 90 aniversari del seu naixement, Campos 1977.

«La dialectologia al col-loqui de Tarragona-Salou», dins Serra d'Or 316, 1986, 37-38. «Presentació», dins Actes de les Segones Jornades d'Estudis de la Llengua Normativa (1985), Montserrat 1987, 7-8.

«Francesc de B. Moll, home i filòleg», dins El Día de Baleares, 23 juny 1987, 4.

«Prefaci» (en col-laboració amb A. Manent), dins Miscel-lània d' Homenatge a Enric Moreu-Rey, vol. I, Montserrat 1988, 5-10.

«Presentació», dins Josep Sanna, Diccionari Català de l'Alguer, L'Alguer-Barcelona, 1988, 9-12.

«Crònica breu d'un col-loqui internacional», dins La Vanguardia, 4 octubre 1988.

«Francisca Veny o l'art de brodar», dins Festes de la Mare de Déu d'Agost 1988, Campos (Mallorca), 1988. 
«A Tolosa de Llenguadoc, el VIII Col-loqui de l'AILLC. La Lingüística», dins Serra d'Or 350, 1989, 26-27.

«Oralitat i llengua nacional», dins Xarxa 20-21 (2. è època), 1989, $27-28$.

«Una joia lexicogràfica», dins Serra d' Or 356, 1989, 64-65.

«Parlament (amb motiu de la denominació de les Escoles Públiques de Campos)», dins S'Escola Nostra 28, 1989, 5-9.

Pregó del Centenari. I Centenari de la Fundació de la Congregació de les Germanes Missioneres dels Sagrass Cors de Jesús i de Maria. Campos: Impremta Roig 1992 (i reproduilt dins Lluc 766, 1992, 15-20.)

«Dialecte i llengua estàndard», dins Festes d'Agost, Campos 1992.

«Prefaci» (en col-laboració amb Jaume Mascaró), dins Societat d' Onomàstica. Butlletí interior, 53, 1993, [Actes del Congrés d'Onomàstica. XVII Col-loqui General de la Societat d'Onomàstica (Barcelona, 27-29.2. 1992) ], 1993, 9-13.

«Ornitònims en la «Historia de Campos» de Francesc Talladas», dins Ressò de Campos, 1993, 7.

«Barcelona, seu del VIII Col-loqui Internacional de l'«Atles Lingüístic Romànic»», dins Serra d'Or 421, 1995, 29.

«Veus salvades del silenci», dins Serra d'Or 433, 1996, 76-77.

«Aina Moll Marquès», dins Anuari de l'Institut d'Estudis Catalans. Curs 1993-1994, Barcelona 1995, 220-223.

«Sobre el Diccionari de l'Institut d'Estudis Catalans», dins Serra d'Or 433, 1996, 25-26. «La paraula, de dol», dins Ressò de Campos 83, 1996, 7-8.

«Joan Coromines, maestro de la etimología», dins La Vanguardia 3 gener 1997, 32.

Entrevista a Diari de Balears, 15 març 1998.

«Sobre l'article dels topònims de les Balears», dins Ressò de Campos 89, 1997, 16.

«Des dels nostres seixanta-cinc anys...», Aplec d'adhesions $i$ col-laboracions a la $V$ Trobada de Quintes i Quintos del 53, Campos, 24 gener 1998.

Solemne investidura de Doctor Honoris Causa al professor Joseph Gulsoy. Discurs de presentació del Professor Joan Veny, Universitat de Barcelona, maig de 1998, 13-16.

«Manuel Sanchis Guarner, dialectòleg», dins Antoni Ferrando i Francesc Pérez i Moragon (eds.), Manuel Sanchis Guarner: el compromís cívic d'un filòleg, Universitat de València, 1998, 158-161.

«Viatge dialectològic», dins Til i Inge Stegmann (ed.), Guia dels Països Catalans, Barcelona, Curial, 1998, 28-33.

Discurs inaugural a Actes de l'Onzè Col-loqui Internacional de Llengua i Literatura Catalanes (Palma, 8-12 setembre 1997), Abadia de Montserrat, 1998, I, 11-15.

«Antoni M. Badia Margarit», dins Ciutadà i filòleg, el Dr. Antoni M. Badia Margarit, Centre Associat de la UNED, Terrassa, 1999, 3-4.

«Erotisme i litúrgia en la toponímia», "La Vanguardia», 30.04.1999.

«Història i normativa del 'mosquit'», La Vanguardia, 18.06.1999.

Parlament de gratitud en ocasió del Reconeixement de Mèrits ' 98 per l'Escola Municipal de Mallorquí de Manacor (5.06.1999), dins Reconeixements de Mèrits '98. Parlaments, imatges $i$ adhesions, «Papers de sa Torre/50», Manacor, Patronat de l'Escola Municipal de Mallorquí, 1999, 41-42. 
«Contacte de llengües: l'adaptació de la jota castellana en mallorquí», in Festes de la Mare de Déu d'Agost. Campos 99, Campos, 1999, 3 pàgs.

«Contacte de llengües: del castellà majo al català maco», La Vanguardia, 24 setembre 1999.

"Origen linguuístic del llinatge Lladó / Lledó», dins Trobada dels Lladó a Campos (19 de setembre de 1999).

«De la nespla al micaco», La Vanguardia, 17 desembre 1999.

"Galleguismes del català», La Vanguardia, 31 març 2000, p. 7.

"Catalanismes del gallec», La Vanguardia, 7 abril 2000, p. 5.

«L'empremta genovesa», La Vanguardia, 26 maig 2000, p. 7.

«Josep Vallverdú, mestre de la llengua», Avui, 2.06.2000, p. 20.

«Sobre els gal-licismes del català», La Vanguardia, 27.10.2000.

«El llegat lingüístic occità», La Vanguardia, 3.11.2000, p. 6 del Suplement

«La normalització del lèxic i l'onomàstica» (moderador de Taula rodona), in Isidor Marí (ed.), Jornades per a la cooperació en l' estandardització lingüística, Institut d'Estudis Catalans, Secció Filològica, Barcelona, 2000, 227.

«De bracet amb la qualitat. Nominació de Dom Josep Massot i Muntaner», dins 25è Reconeixement de Mèrits. Parlaments, imatges, adhesions, Manacor, Patronat de l'Escola Municipal de Mallorquí, 2001, 27-30.

«Vidal Alcover, lingüista», La Vanguardia, 11 maig 2001

«De l'auguri a l'esternut», La Vanguardia, 1 juny 2001.

«La 'Lletra de convit'»(I), La Vanguardia, 22.06.2001.

«La 'Lletra de convit'» (II), La Vanguardia, 6.07.2001.

«Antoni M. Alcover i la dialectologia catalana», Serra d'Or, 507, març 2002, 16-18.

«Atles musical. Una llengua de convit». Una iniciativa de la Direcció General de Política Lingüística del Govern Balear, Assessorament, revisió lingüística i notes lingüístiques de Joan Veny, Barcelona. DL: B-36148-01.

«Cap a una història lingüística dels peixos de les Balears», El Mirall, 132, maig 2002, 24-26.

«El Diccionari català-valencià-balear», Centenari de la Lletra de Convit, Barcelona, Institut d'Estudis Catalans, Publicacions de la Presidència, 2002: 16-21.

«Discurs inaugural del XII Col-loqui Internacional de l'Associació Internacional de Llengua i Literatura Catalanes» (París, Universitat de París IV - Sorbona, 4-10 setembre de 2000), Barcelona, 2003, Publicacions Abadia de Montserrat, I, 9-12

«Discurs de cloenda del XII Col-loqui Internacional de Llengua i Literatura Catalanes de l'AILLC» (París, Universitat Paris IV - Sorbona, 4-10 setembre de 2000), Barcelona, 2003, Publicacions de l'Abadia de Montserrat, I, 13-14.

«En el centenari de la visita d'Antoni M. Alcover a Campos», Festes de la Mare de Déu d'Agost 2003, Campos (Mallorca), 2003, 2 pàgs.

«Francesc de B. Moll, homenot de la linguística catalana», Llengua nacional, 45, 2003, 35-36.

«Francesc de B. Moll, genio de la lexicografía», La Vanguardia, 31.12.2003, Cultura, p. 4. «Tres anys meravellosos», dins Medalla IES Màrius Torres 2004, Lleida, 2004, 24-32. 
"Sobre les mentides de les ungles», Festes de la Mare de Déu d'Agost (Campos, 2004), Campos, Ajuntament, 20-21.

"Mossèn Gabriel Reus i la llengua catalana», dins Homenatge a Mn. Gabriel Reus i Mas, Parròquia de Sant Julià de Campos, 19 de setembre de 2004, Campos: Impremta Adrover, 17-19.

«El Diccionari Figuera». entrevista a Llucmajor de pinte en ample, 259, octubre 2004, 12-13.

«Visita de la Secció Filològica a Pont de Suert (14 de maig de 2004)», Estudis Romànics, $27,2005,524$.

«Simposi Internacional sobre Sintaxi històrica del català», Estudis Romànics, 27, 2005, 534-535

«Sobre l'epistolari entre Maria-Antonia Salvà i Miquel Roig», Festes Mare de Déu d'Agost 2005, Campos, 52-53.

Nota de llibres rebuts sobre Ursula Bedogni-Francesco Ardolino, «dizionario dell'uso dei verbi italiani», 2004; Ventura Castellvell, «El capbreu de Benifallet», Barcelona, 2005; Josep M. Massana, «Diccionari de lleidatanismes», Lleida, 2004; Cosme Aguiló, «Cançons de Cabrera», Palma de Mallorca, 2004, dins Estudis Romànics, 28, 2006, 529-530.

Cròniques sobre els Premis Sant Jordi de l'IEC (2005), ER, 28, 2006, 535-536; Premi Narcís Monturiol a Eulàlia Duran, Premi d’Actuació Cívica a Josefina Salord, ER, 28, 2006, 573; sobre la «Sociedat de Lingüística Aragonesa», ER, 28, 2006, 600.

\section{PRÒLEGS}

José L. Calero López de Ayala, El habla de Cuenca y su serranía, Cuenca, 1981, 9-10.

Daniel Recasens, La parla del Camp de Tarragona (Assaig de síntesi), Tarragona, 1982, 7-9.

Brian L. Mott, Diccionario chistavino-castellano, Zaragoza, 1984, 9-11.

Grup de Recerva Folklòrica d'Osona, El folklore de Rupit i Pruit. II. Narracions, Vic, 1984, 13-15.

Ignasi M. Muntaner Pascual, Els noms de lloc del terme de Sitges $i$ de les terres veïnes, Sitges, 1986, 6.

Empar Guillén, El manuscrit de Pere Segarra. Recull històric d'Ivars d'Urgell i diari de l'autor (1932-1938), Lleida, 1986, 9-19.

(Amb col-laboració amb Joan M. Pujals), Actes del Setè Col-loqui Internacional de Llengua i Literatura Catalanes (Tarragona-Salou, octubre 1985), Abadia de Montserrat, 1986, 5-8.

Miquel Roig, La nostra llar. Poema en vuit cants, Campos (Mallorca), 1987, 9-11.

M. Dolors Farreny i Sistac, Processos de crims del segle XV a Lleida. Transcripció i estudi lingüístic, Lleida, 1986, 1-3.

(En col-laboració amb Albert Manent), Miscel-lània d'Homenatge a Enric Moreu-Rey, I, Publicacions de l'Abadia de Montserrat, 1988, 5-10.

Ramon Amigó, Materials per a l'estudi dels noms de lloc i de persona, $i$ renoms del terme de Reus, Reus, 1988, 11-14.

Emili Casanova, El lèxic d'Antoni Canals, València-Barcelona, 1988, 7-9. 
Josep Sanna, Diccionari català de l'Alguer, L'Alguer-Barcelona, 1988, 9-12.

Carme Vilà i Comajoan, El parlar de la Plana de Vic, Manresa, 1989, 9-10.

Gabriel Reus Mas, Pa pagès, Campos (Mallorca), 1991, 9-10.

Josep Ll. Savall Rom, El vocabulari dels pescadors de Cambrils, Reus, 1991, 11-13.

Cosme Aguiló, La toponímia de la costa de Campos, Campos (Mallorca), 1991, 9-11.

M. Dolors de Ribot i Mundet, Problemàtica de l'adquisició del sistema fonemàtic de la Ilengua catalana a les comarques de Girona, Abadia de Montserrat, 1992, 5-6.

Carles Duarte, Curs d' Història de la llengua catalana, «Com», extra núm. 6, Barcelona, $1992,6$.

Javier Terrado Pablo, La lengua de Teruel a fines de la Edad Media, Teruel, 1991, 1-4.

Pere Navarro, El parlar de la Fatarella (Terra Alta). Estudi fonètic, morfosintàctic i lèxic, Calaceit, 1992, 11-12.

Jordi Farré / Andreu Moix, Els noms de casa de Llorenç $i$ de Maldà, Barcelona (Biblioteca Filològica, XXIX), 1993, 7-8.

Ramon Sistac, El ribagorçà a l'Alta Llitera. Els parlars de la Vall de Sosa de Peralta, Barcelona (Biblioteca de Dialectologia i Sociolingüística, III), 9-11.

(En col-laboració amb Jaume Mascaró), Actes del Congrés d'Onomàstica (Barcelona, 27-29 febrer 1992), Barcelona, 9-13.

Lluís Gimeno Betí, Estudi lingüístic dels parlars de les comarques del Nord de Castelló, Castelló de la Plana, 1994, 7-9.

J. Rosselló - J. Rallo - J. Sacarès, Les Figueres mallorquines, Fundació Illes Balears, 1994, 5-6.

Antoni Ignasi Alomar, L'armament i la defensa a la Mallorca medieval. Terminologia, Palma, 1995, 7-8.

Bartomeu Font Obrador, Hostoria de Llucmajor, VI, Mallorca, 1995, 7-11.

Joan Ponsoda Sanmartín, El català i l'aragonès en els inicis del Regne de València segons el llibre de Cort de Justícia de Cocentaina (1269-1296), Alcoi, 1996, 9-10.

Damià Huguet, Les fites netes, Mallorca, 1996, 9-13.

Joaquim Viaplana, Dialectologia, Universitat de València, 1996, 13-15.

M. Rosario Cabrera, El món mariner a Dénia. Estudi etnolingüístic, Ajuntament de Dénia, Institut d'Estudis Comarcals de la Marina Alta, Institut de Cultura «Juan GilAlbert», 1997, 11-12.

Joan Miralles, Corpus d'antropònims mallorquins del segle XIV, Barcelona,, Institut d'Estudis Catalans, Repertoris de la Secció Filològica, III, 1997, 7-10.

José Enrique Gargallo / Miquel Àngel Pradilla, El joc ancestral de la paraula. Llengua, cultura popular i refranyer a Rossell (Baix Maestrat), Benicarló, 1997, 11-13.

Homenatge a Arthur Terry, Estudis de Llengua i Literatura Catalanes, 25/,, Montserrat, 1997, 5-7.

Montserrat Alegre, La llengua i els parlants, Barcelona, Santillana, 1998, 3-4.

Antoni Mas-Joan Pomar Mir, Campos, dibuix i paraula, Campos, Impremta Adrover, 1998, 7-11.

Gabriel Reus Mas, Els malnoms de Campos, Campos, Impremta Adrover, 1998, 7 pàgs.

Mercè Lorente, Tipus de discurs, Barcelona, Santillana, 1998, 2. 
Anna Bartra, L'estructura de la llengua, Barcelona, Santillana, 1998, 3.

Cels Calviño / Joan Clar, Les barraques de Llucmajor, una arquitectura popular. Antropologia i etnografia de la foravila llucmajorera, Palma, Consell de Mallorca, 1999, 9-10.

Montserrat Barri i Masats, Aportació a l' estudi dels gal-licismes del català, Barcelona, IEC, 1999, 11-13.

Montserrat Badia, Diftongs i africats, dues qüestions polèmiques de la fonologia catalana, Barcelona, 2000, Curial-Publicacions de l'Abadia de Montserrat, 7-8.

Brian Mott, Diccionario etimológico chistabino-castellano castellano-chistabino, Zaragoza, Institución Fernando el Católico, Diputación de Zaragoza, 2000, 7-9.

Corbera Pou, Jaume (2000): Caracterització del lèxic alguerès, Universitat de les Illes Balears, 11-12.

Vila Pujol, M. Rosa, Corpus del español conversacional de Barcelona y su área metropolitana, 2001, Universitat de Barcelona, I-V.

M. Àngels Diéguez Seguí, Clams i crims a la València medieval (1279-1321) segons el Llibre de Cort de Justícia, València, 2002,7-9.

Ballester, Miquel - Lladó, Fàtima (2002): Entre poc i massa sa mesura passa. Pesos $i$ mesures de Mallorca abans del sistema mètric decimal, Palma de Mallorca, 9-11.

M. Alegre, A. Bartra, M. Lorente, A. Planelles, F. Vernet, Llengua catalana i Literatura, Barcelona, Santillana, 2002, 3.

61 ninots de Josep Vallverdú, Doctor Honoris Causa. Edició en homenatge, Lleida, Universitat de Lleida, Departament de Filologia Catalana i Comunicació, 18 de març de 2004, 5-6.

Miquel Duran, Noms i descripcions dels peixos de la mar catalana, I. Agnats. Condrictis. Osteïctis (1. ${ }^{a}$ part), Mallorca: Moll (en premsa).

Brauli Montoya, Historia de la llengua catalana en un territori de frontera. Petrer (Vinalopó Mitjà) (en premsa).

R. Botet - C. Camps, Diccionari francès-català, El Trabucaire, 2006 (en premsa).

\section{RECENSIONS}

D'Archivo de Filología Aragonesa, toms III, IV i V, dins Revista de Filología Aragonesa, 29, 1955, 445-450.

Dins Índice Histórico Español, núms. 12 (1955). 13 i 14 (1956) del vol. II; núms. 24, 25 i 26 (1956) del vol. V i núm. 29 del vol. VI (1960.)

De M. Alvar, Endechas judeoespañolas, dins Boletim de Filologia (Lisboa), 16, 1957, 365-367.

De Joan Miralles, Un poble, un temps, dins Diario de Mallorca, 14-03-1974.

D'Antoni M. Badia Margarit, Vint-i-cinc anys d' estudis sobre la llengua i la literatura catalanes. I. La llengua, Barcelona, 1976, dins Serra d'Or, núm. 209, 1977, 41.

De Loreto Busquets, Aportació lèxica de Josep Carner a la llengua literària catalana, Barcelona, 1977, dins Serra d'Or, núm. 226, 1977, 41.

De Joan Coromines, Diccionari etimològic i complementari de la llengua catalana (I, Barcelona, 1980), dins Serra d'Or, núm. 246, 1980, 38. 
De Lázaro Carreter, Diccionario de términos filológicos (2. ${ }^{\text {a }}$ ed., Madrid 1962), dins Estudis Romànics, 16, 1971-1975 [1981], 233-237.

D'Amadeu-J- Soberanas, Paleotoponímia medieval: «Llentisclell», «Els Estinglells» $i$ altres descendents de LENTISCUS en català, article deTreballs de la Secció de Filologia i Història Literària (Institut d'Estudis Tarraconenses), I (Tarragona 1980, 161.177), dins Societat d'Onomàstica. Butlletí interior, 4, 1981, 40-41.

D'Albert Manent, Els noms de lloc del terme i del poble de Capafonts, extret de Treballs de la Secció de Filologia i Història Literària, II (Tarragona 1981, 9-67), dins Societat d'Onomàstica. Butlletí interior, 8, 1982, 31-33.

De V. Biete i Farré, Toponímia de Cabacers i el seu terme (Barcelona 1983), dins Societat d'Onomàstica. Butlletí interior, 14, 1983, 42-43.

De Jordi Mir, Els noms de lloc del terme de Tremp i del seu agregat Claret (Tremp 1983), dins Societat d' Onomàstica. Butlletí interior, 14, 1983, 43-44.

D’Eugeni Perea, La Morera de Montsant i el seu terme municipal. Toponímia (Santes Creus 1984), dins Societat d'Onomàstica. Butlletí interior, 18, 1984, 58-60.

De Vinyet Panyella, Recull de motius de la vila de Sitges (segles XVI-XX) (Sitges 1987), dins Societat d'Onomàstica. Butlletí interior, 32, 1988, 41-42.

De Josep Veciana i Aguadé, Recull de topònims i antropònims del terme municipal de Renau, article de Treballs de la Secció de Filologia i Història Literària (Institut d'Estudis Tarraconenses Ramon Berenguer IV), V (Tarragona 1990, 59-143), dins Societat d'Onomàstica. Butlletí interior, 46, 1991, 80-81.

D'Isabelle Secretan, Traité d'ichtyonymie catalane. De l'origine des noms de poissons marins (Dissertationen der Universität Salzburg, 26), Wien 1988, dins Zeitschrift für Romanische Philologie, 109, 1/2), 1993, 229-234.

De Jordi Bruguera, El vocabulari del Llibre dels fets del rei en Jaume, València-Barcelona, 1999, dins Arxiu de Textos Catalans, 21, 2002, 757-758.

De Germà Colón, Estudis de filologia catalana i romànica, València-Barcelona, dins Estudis Romànics, 25, 372-375.

De Cosme Aguiló, Toponímia i etimologia, Barcelona, 2002: PAM, dins Estudis Romànics, 27, 377-380.

De J. Monturiol i E. Domínguez, El parlar de la Garrotxa, Girona: Ràdio Olot, 2005, 382-385.

D’Emilio Barriuso, Atlas léxico marinero de Asturias, Oviedo, Real Instituto de Estudios Asturianos, 2002, dins Revista de Filoloxía Asturiana, 3 (en premsa).

Sabina Canobbio - Tullio Telmon, Atlante Linguistico ed Etnografico del Piemonte Occidentale (ALEPO), Presentazione e guida alla lettura, Torino, 2003; I-III II mondo vegetale. Funghi e licheni, Torino, 2004; I-III Tavole scelte, Torino, 2004, dins Estudis Romànics, 28 (2006), 444-447. 